\title{
PERSPECTIVE
}

\section{Primary care and ophthalmology in the United Kingdom}

\section{S F Riad, J K G Dart, R J Cooling}

The National Health Service is now primary care led. There are different definitions for primary care and in this review they are analysed and related to ophthalmology to produce a working definition for ophthalmic primary care, summarised as the provision of first contact care for all ophthalmic conditions and follow up, preventive, and rehabilitative care of selected ophthalmic conditions, in a variety of settings, by a diverse workforce. The attributes of primary care are first contact, accessibility, continuity, longitudinality, comprehensiveness, coordination, equity, and accountability. The delivery of ophthalmic primary care should be governed by these and evaluated accordingly. The clinical content of primary care consists of the first presentation of disease, the management of minor illness and trauma, the recurrence of disease, the follow up and support of some chronic conditions, and the delivery of preventive health care. Planning for ophthalmic primary care needs to take service requirements of these categories of disease into account. Primary care research is abundant in ophthalmology but needs to be more structured and targeted. Ophthalmic primary care itself is urgently in need of recognition and formal adoption by the profession.

See end of article for authors' affiliations

Correspondence to John K G Dart, Moorfields Eye Hospital, City Road, London ECIV 2PD, UK. j.dart@ucl.ac.uk

Accepted for publication 30 October 2002
I $\mathrm{n}$ the United Kingdom, the National Health Service is now primary care led. ${ }^{1}$ This has prompted a widespread interest in primary care. The practice of primary health care parallels the organisation of the human race into communities, ${ }^{2}$ and ophthalmology has developed its own role in this field. The current approach to primary care is philosophical, systematic and policy oriented. This review summarises the concepts of modern primary care and relates these to ophthalmology.

\section{THE EVOLUTION OF PRIMARY CARE}

The global beginnings of structured primary care are traced to the United Kingdom following the National Health Insurance Act of 1911, when the arrangement of a community medical practitioner for first contact care was established. ${ }^{2}$ This system of medical care was consolidated with the NHS Act of 1946 and primary care was taken to indicate first contact care and a personal physician who is close to the patient and his family and can therefore coordinate the health needs of the patient, act as gatekeeper to the hospital service, and assist in the delivery of social care and public health.

In the mid-1960s, primary care became an issue in the United States, consequent to flourishing specialisation resulting in a rapid decline in the number of general practitioners (GPs). Policies to promote primary care at that time focused on the development of the specialty of family medicine. ${ }^{3}$ The tradition of regarding primary care as an initial level of clinical care was therefore confirmed in the United States.

In 1979, the World Health Organization (WHO), in its Alma-Ata Declaration, advocated the central role of primary care in the delivery of health care and defined it in terms of medical care that is closely related to the community and public health activities. Together, primary care and the public health services would deliver essential health care. ${ }^{4}$ Given that developing countries are the majority members of the United Nations, the WHO definition incorporated public health elements that are important to these countries, but perceived by developed countries as irrelevant to their needs. ${ }^{5}$

However, the growing contributions of epidemiology and the social and behavioural sciences were drawing attention to the socioeconomic, environmental, and behavioural factors that affect the health of individuals and populations. ${ }^{3}$ The concept of community oriented primary care, therefore, started to gain ground in the United States $^{3}$ and Europe. ${ }^{6}$

The primary care movement remained inactive until the mid-1990s, when governments recognised the potential of primary care in strategies for the delivery of health care. ${ }^{378}$ In the United Kingdom, a policy of a primary care led National Health Service was declared. ${ }^{1}$

An intensive debate followed. In the United States, where primary care was a relatively new concept, the debate focused on how to build the perfect primary care. ${ }^{39}$ In the United Kingdom, the emphasis was on reforming and expanding the existing system. As there was some interchange between the two debates, this review will refer to US input when relevant.

\section{THE DEFINITION OF PRIMARY CARE}

There is no one single definition for primary care. A study by the Institute of Medicine of the United States in 1996 found that since it was first used in 1961, the term primary care had been defined in various ways, using a number of elements in one or more combinations. They included the workforce, the activities, the level of care, the setting, and the desired attributes. It had also been defined as a strategy for organising the healthcare system as a whole.' 
Despite multiple definitions, two distinct approaches emerge. $^{310}$ The first is a broad public health type which stresses public health issues and the second is a narrower healthcare system approach, which stresses clinical care.

The public health approach is exemplified by the WHO definition, which defines primary care as "essential health care made universally accessible to individuals and families in the community by means that the community and country can afford. It forms an integral part both of the country's health system of which it is the nucleus and the overall social and economic development of the community." It provides promotive, preventive, and rehabilitative services which will include at least proper nutrition, safe water supply, basic sanitation, maternal and child care, immunisation, health education and, finally, the appropriate treatment of common diseases and injuries. ${ }^{4}$

Primary care, which is defined using the above approach, is often referred to as "primary health care" ${ }^{45}$ or "community oriented primary care."

In contrast, the healthcare system definition focuses on personal medical services for the individual. This is exemplified by the widely quoted Starfield and Institute of Medicine definitions, which although originating in the United States, have been adopted by working groups in the United Kingdom, ${ }^{11-13}$ as a point of reference, in the debate on the development of the primary care led NHS.

The Institute of Medicine defines primary care as " the provision of integrated, accessible, health care services by clinicians who are accountable for addressing a large majority of personal health care needs, developing a sustained partnership with patients, and practicing in the context of family and community." In the Starfield definition, "primary care is first contact, continuous, comprehensive and coordinated care provided to individuals and populations undifferentiated by age, gender, disease or organ system." ${ }^{14}$

In the United Kingdom, where primary care has been practised empirically since the Apothecaries Act of 1815, ${ }^{2}$ definitions have evolved from practice and focused on first contact with the patient, the workforce, the setting, and activities. ${ }^{12} 15$

The Royal College of General Practitioners defines primary care as "front line care in first contact with the public."15 The Medical Research Council defines primary care as health services which provide the first (primary) point of contact for individual members of the public (in contrast to secondary [referral] services), although it accepts that some of these services are provided by hospitals. It also points out that primary care incorporates elements of social care, community care, and primary caring provided by families or unpaid individual members of the public. ${ }^{12}$

In ophthalmology, workers who specialise in ophthalmology in developing countries appear to adopt the WHO definition, as exemplified by the work of Professor Barrie Jones ${ }^{16}$ and the Department of Preventive Ophthalmology of the Institute of Ophthalmology in London. ${ }^{17}$ Ophthalmic primary care in the United Kingdom has never been formally defined, but the literature suggests the healthcare system approach, with publications written by practitioners on primary care patients and services. There is however a considerable body of literature on populations, but the two approaches have not met in a common agenda yet.

\section{THE ATTRIBUTES OF PRIMARY CARE}

Most of the contributions on this subject came from the United States where it is proposed that in order to be designated as primary care, a service needs to be characterised by (1) first contact, (2) accessibility, both socioorganisationally and geographically, (3) continuity, where care is provided as an uninterrupted succession of events either by only one person being in charge or the continuous availability of medical records, (4) longitudinality, where individuals identify with a source of care as their own, (5) comprehensiveness, where a broad range of services for a broad range of problems is provided directly or elsewhere by arrangement, (6) coordination, which is the availability of information about previous problems and services, recognition of their significance in the current episode of care, referral, and the transfer of this relevant information to the other health professionals involved in the current episode, (7) equity, where care is provided to all individuals and populations without differentiation, and (8) accountability, where the service is accountable for the provision of all of the above and patients are accountable to sustain the relation, convey information, undertake preventive care, and participate in the treatment plan timely and accurately. ${ }^{9}{ }^{18} 19$

Although some of these attributes are applicable to other divisions of health care, they are mandatory in primary care and this is an important distinction. Indeed, it is by these attributes that the quality of a primary care service is evaluated..$^{9}$

\section{THE PRINCIPLES OF GOOD PRIMARY CARE}

Publications emanating from the United Kingdom often refer to the above attributes, but the official UK view ${ }^{20}$ is that the principles of good primary care include (1) quality, in which professionals are knowledgeable about the conditions that present in primary care and the people to whom they are offering services and that services are coordinated with no service gaps, (2) fairness, in that services should not vary widely in different parts of the country and that primary care should receive an appropriate share of NHS resources, (3) accessibility, in which services should be reasonably accessible when clinically needed regardless of age, sex, ethnicity, and health status, (4) responsiveness, in that services should reflect the needs and preferences of the people using them and the demographic and social needs of the area they serve, and (5) efficiency, in which services are based on scientific evidence and resources are used efficiently.

There is clearly an overlap between the UK and US approaches, but there are also differences which reflect the UK's long experience in this area and its quest for reform.

\section{CHARACTERISTICS OF THE PRIMARY CARE LED NHS}

Primary care, as described above, should not be confused with a primary care led NHS. The latter is a strategy for service delivery and the development of the former is important and inevitable for the successful implementation of this strategy.

The characteristics of the primary care led NHS include the shifting of some elements of care out of hospital, the proliferation of managerial staff to cope with increasing responsibilities as a result of expansion of services and governance, the availability of reliable, relevant information, the involvement of nurses and professions allied to medicine to lessen the doctor's work load (skill mix), the adoption of a public health perspective by GPs, sustainability, and diversity in the nature, organisation, and operations of the different primary care providers. ${ }^{21}$

Ophthalmology was one of few disciplines to have a formal community element in the NHS Act of 1946, with the formation of the "temporary" Supplementary Ophthalmic Services. These were subsequently found to be indispensable and were made permanent in the Health Services and Public Health Act 1968 and renamed the General Ophthalmic Services (GOS). Over the years, the responsibilities of the GOS were increased and they now include contact lens work, glaucoma screening, ${ }^{22}{ }^{23}$ selective diabetic retinopathy screening ${ }^{24-26}$ and experimental trials of the follow up of glaucoma patients, ${ }^{27}$ cataract surgery, ${ }^{28}$ and the referral of cataract patients directly to the hospital. ${ }^{29}$ Extending the optometrists' role to treatment of disease and becoming the principal providers of primary 
ophthalmic care in the community has been proposed ${ }^{20}$ and the prescription of therapeutic drugs by optometrists is being considered, ${ }^{30}$ but these suggestions have not been approved by the Royal College of Ophthalmologists. ${ }^{31-33}$

Dart $^{34}$ in 1986 suggested conducting weekly ophthalmic sessions in general practices and found that an ophthalmologist could meet the ophthalmic needs of a community, served by seven GPs, in one clinical session a week, when approximately 10 patients would be seen. This was the minimum size of practice in which such a service could be viable in terms of cost effectiveness. Gillam et $a l^{35}$ in 1995 investigated the benefits and costs of a similar model and found that it was popular with patients and GPs, but the unit costs per patient compared unfavourably with those of conventional outpatient treatment and its educational impact was limited. Chopdar ${ }^{36}$ in 2001 proposed a model in which a community ophthalmologist conducts clinics in primary care trusts and refers the more complicated cases to the local hospital eye service. Recently, Blach ${ }^{37}$ suggested a community ophthalmic team in which all of the ophthalmic workforce would take part, but with some change in outlook. Ophthalmologists would need to acquire a greater awareness of community needs and obtain training in the leadership of a team of eye care professionals, optometrists would work as part of a community team, and orthoptists would expand their role outside ocular motility disorders. The role of the nurse practitioner would be further enhanced and charities would be associated with the team.

Skill mix in ophthalmology has been discussed as far back as 1986 when Jones et $a l^{38}$ described a substantial role for nurses in an ophthalmic accident and emergency (A\&E) department, showing that, in their series, nurses had treated and discharged $36.5 \%$ of patients and initiated treatment in $20.3 \%$ of patients. Oster et al ${ }^{39}$ explored the potential role for optometrists in the clinical appraisal of new referrals to the hospital and found a high level of diagnostic accuracy. The multidisciplinary model in hospital based ophthalmic primary care services has been reported to be in use in Warrington, ${ }^{40}$ Liverpool, ${ }^{41}$ and London. ${ }^{42}$ The Warrington study, although evaluating the model as a whole and not concentrating on its skill mix aspect, reported a maximum waiting time of 2 weeks, no unsatisfactory responses via a patient satisfaction questionnaire, a majority of GPs satisfied by the service to different degrees via a GP questionnaire, and considerable saving in consultant time in eliminating the need to allocate priority.

Aylward and Parmar described an ophthalmic electronic patient record which will enable the prompt exchange of information between primary care and the hospital as part of the NHS IM\&T (Information Management and Technology) strategy. ${ }^{43}$ Murdoch demonstrated the potential value of telemedicine in the examination of ophthalmic patients in a number of primary care activities outside the hospital. ${ }^{44}$

\section{THE DELIVERY OF PRIMARY CARE}

In the United Kingdom, primary care is delivered via a network of services to which general practice is central. It is delivered via the health services, social services, voluntary organisations, the private sector and unpaid carers, in a variety of settings including GP surgeries, health centres, hospitals, day centres, residential care units, schools, people's own homes, pharmacies, and dental surgeries. ${ }^{12}{ }^{45}$

In the community, ophthalmic primary care is delivered in (1) general practice by GPs, ${ }^{46}$ (2) optometrists' offices by optometrists or ophthalmic medical practitioners (OMPs), ${ }^{47}$ (3) homes and community centres where preschool children are visually screened by GPs, health visitors, or orthoptists, ${ }^{48}$ (4) schools where pupils are visually screened by medical officers, nurses, or technicians, ${ }^{49}$ and (5) pharmacies where individuals seek advice from pharmacists for minor eye conditions and are able to obtain a limited variety of over the counter products.
In the hospital, primary care is delivered in (1) general A\&E departments by casualty doctors, ${ }^{50-52}$ (2) ophthalmic A\&E departments by junior ophthalmologists, ${ }^{53}$ (3) hospital based primary care centres by ophthalmologists, nurses, optometrists, and orthoptists, ${ }^{40-42}$ (4) primary care outreach clinics in community hospitals with staffing similar to (3), ${ }^{42}$ and (5) outpatient departments ${ }^{54}$ by all grades of ophthalmologists.

The ophthalmic workforce also includes social workers ${ }^{56}$ and members of the public working in the ophthalmic related charities that provide support and counselling.

The capability and training of the different members of the ophthalmic primary care workforce has been discussed. Dart $^{34}$ examined diagnostic accord between an ophthalmologist and GPs by comparing the diagnoses in a small sample of patients and found that conjunctivitis and cataract may be overdiagnosed by GPs. Sheldrick et al ${ }^{57}$ similarly found a small range of diagnoses and non-accord in diagnosis in $42 \%$ of cases, but concluded that most cases of misdiagnosis have no serious consequences for the patient. The prescribing pattern of GPs has come under criticism in the debate surrounding topical steroids, ${ }^{58}$ and their overprescribing and underprescribing of topical antibiotics was also noted..$^{380}$

The period and content of undergraduate ophthalmology courses in British universities is regarded as inadequate for the skills needed in primary care. ${ }^{46}{ }^{61-63}$ As a result, many GPs admit to lack of confidence in dealing with ophthalmic cases. ${ }^{61}$ Postgraduate courses are more satisfactory from the point of view of GPs but they have not been shown to alter facilities, confidence, or understanding. ${ }^{62}$ Ophthalmic posts during the vocational training of GPs appear to be the most satisfactory mode of training..$^{63}$

Lack of confidence was also found among casualty officers in a UK survey ${ }^{52}$ and patient assessment in a general A\&E department was noted to be incomplete. ${ }^{51}$ However, in a detailed study of one unit over a 12 month period, Edwards found that the majority of patients were managed and discharged by the A\&E medical staff with no serious pathology missed or hospital admission delayed. ${ }^{50}$

Nurses were shown to be capable of managing minor conditions and successfully triaging patients in ophthalmic casualty departments and over the telephone. ${ }^{38}{ }^{64-66}$

Although the diagnostic accuracy of optometrists appears to be variable according to the part of the eye examined, ${ }^{67}$ it has been shown that targeted training of optometrists for specific diagnostic tasks results in a high degree of accuracy. ${ }^{68}$

The difference that orthoptists' participation makes in the visual screening of children, in terms of specificity and sensitivity, ${ }^{69}$ and their ability to detect subtle conditions, has been demonstrated. ${ }^{48} 49$

The current practices of ophthalmic primary care have never been evaluated in one coherent study or indeed has any model been evaluated in its entirety. Apart from the Dart, ${ }^{34}$ Gillam et al, ${ }^{35}$ and Warrington ${ }^{40}$ models, which examined more than one element, the rest of the studies focused on one particular aspect, as demonstrated by the various studies on the capability of the workforce.

\section{CONTENT OF PRIMARY CARE}

The Working Group on R\&D in Primary Care for the NHS Executive categorised the clinical content of primary care as (1) the first presentation of most serious disease including recurrence of disease treated in hospital, (2) the treatment of most minor illness, (3) the treatment of some chronic illness, and (4) most preventive health care. ${ }^{13}$

The disease content of general practices in the United Kingdom is periodically reported..$^{70}$ These sources include data about eye conditions, but diagnosis is imprecise. The General Practice Research Database has been collecting records on general practice patients since 1990 and may include more 
details, as record entry is episodic and includes management and hospital feedback..$^{71}$

Clinical diagnostic series have been reported from almost all ophthalmic primary care settings. These include general practice, $^{72}$ health centre, ${ }^{3435}$ general A\&E, ${ }^{50}$ ophthalmic A\&E, ${ }^{38-75}$ hospital based primary care, ${ }^{42}$ ophthalmic outpatient clinic, ${ }^{54}$ optometrist office from the viewpoint of an $\mathrm{OMP}^{47}$ and optometrist offices via national surveys. ${ }^{76-78}$

Authors attempted to cover the entire spectrum of primary care conditions by combining types and sources of patients. Significant contributions came from Jones et al, ${ }^{38}$ when they included old patients in their casualty study, Sheldrick et al, ${ }^{79}$ when they used the concepts of demand incidence and episode rates by including all first contact settings in a defined population, and Bhopal et al, ${ }^{75}$ who included different hospital settings in the same study.

While these studies clarify the content of ophthalmic primary care, especially in relation to patient characteristics and their relevance to diagnosis, the real clinical content of primary care, as categorised above, ${ }^{13}$ is not known.

\section{THE PRIMARY-SECONDARY INTERFACE}

Issues at the primary-secondary interface include variation in referral rates, appropriateness of referrals, decision to refer, outcome of referrals, and communication. ${ }^{45} 80$

In ophthalmology, there is a unique primary-primary interface between the optometrist and the GP. The primarysecondary interface is principally between the hospital service and the GP although optometrists may be involved. ${ }^{78}$ An additional primary-secondary interface exists between the primary care services within the hospital and the ophthalmic outpatient clinics.

The interface most widely studied is that between the optometrists and the GP, as part of the ongoing debate on direct referrals to hospitals by optometrists. Since the Opticians Act 1958 optometrists are required to notify the GP or refer the patient when an ocular abnormality is detected, as a legal requirement. The National Health (Primary Care) Act 1997 has relaxed this legislation and optometrists are now allowed to use their professional judgment under the regulation of the General Optical Council.

Not all cases referred to the GP by optometrists are referred to the hospital eye service. Some are treated by the GP, referrals are deferred in some cases especially for cataract, ${ }^{82}$ and some cases are referred to non-ophthalmic departments-for example, neurological cases.

Communication between the optometrists and the medical profession is usually via the GOS 18 (General Ophthalmic Services 18) form. There is no legal requirement for optometrists to use this form and research has shown that not all optometrists use it or enter information in detail. ${ }^{6781}$ Similarly, it was found that only a small proportion of ophthalmologists return their findings to optometrists on the GOS $18 .^{81}$

Kheterpal et $a l^{83}$ examined letters of referral to the A\&E department of a large regional ophthalmic unit and found that information was poorly recorded and that over half of the referrals did not constitute accidents or urgent conditions.

\section{THE HOSPITAL AND PRIMARY CARE}

The International Hospital Federation sponsored a British study on NHS hospitals and primary care, ${ }^{84}$ which found a diverse role for hospitals in this area. The Conference of Academic Organisations in General Practice included a role for the secondary services in which they would be in constant consultation with primary care and seeking to find the best way to support it. ${ }^{11}$

The role of the A\&E departments of inner city hospitals in the provision of primary care was researched in a landmark project in King's College Hospital in London. ${ }^{85}$
Another hospital contribution is in the provision of specialist outreach clinics. Two models have been described-namely, one in which the specialist outpatient clinic is much the same as that in the hospital, but takes place in the community (the shifted model) and another in which there is collaboration between consultant and GP (the liaison attachment model) ${ }^{86}$

In shared care schemes, GPs and community health staff take on some or all of the routine management of patients that was traditionally done in outpatient hospital departments, according to an agreed protocol. ${ }^{45}$

The role of the hospital in ophthalmic primary care is central. The hospital delivers primary care in a number of ways as explained above. In addition, it participates in glaucoma shared care schemes as explained by Hitchings. ${ }^{55}$ Some of the results of the Bristol shared care glaucoma study to which he refers have now been reported. For the purpose of this review, two main issues stand out, firstly, that after 2 years, there are no statistically significant differences in outcome between patients followed up in the hospital eye service and by community optometrists ${ }^{87}$ and, secondly, that the cost of managing ophthalmic patients in the community needs to be examined carefully to establish whether it is economic, ${ }^{88}$ as also demonstrated on other occasions. ${ }^{34} 35$

The input into diabetic retinopathy screening by hospital based ophthalmologists was taking place for many years before routine screening became a reality. ${ }^{89}$ The literature has evidence of trials on combinations of tests, workforce, settings and procedures, initiated, assessed, and reported by hospital based ophthalmologists. ${ }^{90}$ The current debate on visual deficits in the elderly ${ }^{91}$ was initiated by the observations of hospital based ophthalmologists who pursued the subject until it gained its current prominence. ${ }^{92-94}$ In their review of screening for visual deficits in children in the United Kingdom, Rahi et $a l^{95}$ stressed the importance of the input of the ophthalmic community and its position to take the lead.

In addition, the hospital eye service is the main setting for the training and continuous medical education of most members of the ophthalmic primary care workforce.

\section{EPIDEMIOLOGY, PUBLIC HEALTH, AND PRIMARY CARE}

Epidemiology and public health are population sciences. They are therefore closely related to primary care, as discussed above. In developed countries, these disciplines are concerned with issues relating to the planning of services, disease risk, sources of morbidity in the community, and equity. The latter includes the health of, and services for, isolated or underprivileged groups like the elderly, the socially deprived, ethnic minorities, and refugees.

There are many epidemiological studies in ophthalmology and reviewing them all is outside the scope of this work, particularly as many of diseases explored are the remit of the secondary services. We will concentrate on work relating to equity, because this is an important attribute of primary care.

The presence of undetected ocular disease or uncorrected visual acuities among the elderly has been reported in community based studies, representing different types of community, ${ }^{9496}$ and also hospital based studies on ophthalmic ${ }^{93}$ and non-ophthalmic patients. ${ }^{92}$ The quality of the visual screening of this age group in general practice was questioned. ${ }^{97}$ Hillman drew attention to the predicament of the elderly in keeping up with hospital appointments, ${ }^{98}$ prompting the reader to question whether this is a group for whom transfer of care to the community might genuinely be needed.

Recently, Fraser et al ${ }^{99}$ demonstrated consistent evidence of the association between the late presentation of glaucoma and a lower socioeconomic status.

Epidemiological studies on ethnic minorities included the prevalence of eye disease and of age related cataract in Asians 
in Leicester, ${ }^{100}{ }^{101}$ the prevalence of eye disease in Indians in Southall in London, ${ }^{102}$ and the prevalence and risk factors for hypertensive retinopathy ${ }^{103}$ and the risk factors for glaucoma in Afro-Caribbeans living in London. ${ }^{104}$

There are few studies on the ophthalmic needs of refugees in the United Kingdom. In a general study of a Vietnamese refugee population living in Greenwich in London, it was reported that there was unfamiliarity with ophthalmic care, ${ }^{105}$ thus confirming isolation and lack of information about the health services, which were described among other difficulties experienced by refugees, in a review on their health needs. ${ }^{106}$

\section{QUALITY AND PRIMARY CARE}

Quality and primary care are associated in a number of ways-namely, (1) the question of whether good quality health care is attainable via a primary care focused health service, ${ }^{14} 107(2)$ the question of whether the above attributes of primary care are sufficient for promoting good quality primary care $^{18}(3)$ defining appropriate performance indicators and outcome measures for a particular primary care system, ${ }^{18} 108$ and (4) the feasibility of using the Donabedian classification (structure-process-outcome), which is a widely used method for assessing the quality of medical care, ${ }^{109}$ in the evaluation of primary care systems. ${ }^{18}$

Studies on the quality of ophthalmic primary care have mostly concentrated on specific services, training and performance of the workforce, and communication between them, as discussed above.

\section{THE CLINICAL GOVERNANCE OF PRIMARY CARE}

The principles of clinical governance apply in primary care. ${ }^{110}$ Audit, risk management and the practice of evidence based medicine in primary care have been adequately discussed in publications specifically written for general practice, but to our knowledge, there are no publications on the clinical governance of ophthalmic primary care.

\section{OPHTHALMIC PRIMARY CARE-A DISCUSSION}

We have so far summarised the debate on modern primary care, described the current scene in this area of ophthalmology and related them to each other, when possible. We have demonstrated that ophthalmic primary care in the United Kingdom has kept up with developments at both national and international levels.

However, it is noticeable that apart from the response from the Royal College of Ophthalmologists to suggestions for ophthalmic primary care regarded as unacceptable, ${ }^{31}{ }^{111}$ there has been a conspicuous absence of ophthalmic representation in primary care forums. ${ }^{112}$ In addition, the National Research Strategy for Ophthalmology, ${ }_{13}^{13}$ published recently by the Royal College of Ophthalmologists, did not include primary care.

A change in outlook is needed because ophthalmology, especially in the United Kingdom, is distinguished by a number of characteristics that set it apart from other specialties in relation to the primary care debate. These include (1) the advanced technological skills and instruments needed for an initial accurate diagnosis, (2) the limited training in ophthalmology in undergraduate courses in British universities, (3) the frequent association of ophthalmic disease with non-ophthalmic conditions, (4) the strong presence of an optometry workforce in the community, (5) the surgical orientation of ophthalmic training, which does not match its huge outpatient load, (6) the association of much of ophthalmic disease with the elderly, and (7) the end point of failure of treatment is blindness and not death, with a few exceptions.

At this point, we propose the following working definition for ophthalmic primary care from which we will take our discussion forward.

\begin{abstract}
"Ophthalmic primary care is the provision of first contact care for all ophthalmic conditions and the follow up, preventive, and rehabilitative care of selected ophthalmic conditions. It can be delivered in a variety of settings and by a diverse workforce, but in strict, efficient, and timely coordination, to attain the best clinical outcome possible for the patient. A service is designated as ophthalmic primary care, only if appropriately integrated with the patient's main primary care provider, in order to ensure continuity, longitudinality, and comprehensiveness in the overall care of the patient. The primary care ophthalmic service itself should be accessible, equitable, knowledgeable, responsive, and efficient. In these aims, it is supported by the population sciences which identify the medical and service needs of the population served."
\end{abstract}

Currently, ophthalmic primary care in the United Kingdom is practised in different settings and by a variety of practitioners who are interdependent, both in their expertise and their accessibility for the patient. This diversity is therefore inevitable. The challenge to those interested in reform is to bring together all the elements of the current scene into one coherent system, working in harmony, to deliver the best clinical outcome. This can be achieved by bringing all these elements together in one setting or by continuing with diverse settings but defining the role of each group of practitioners, according to their capability, and ensuring clear and timely communication between them, with no inconvenience or loss to the patient.

The above definition proposes that primary care services should be organised around delivering the best clinical outcome for the patient in his passage through primary care. It is our view that unless these outcomes are defined, for the relevant conditions, the practice of primary care cannot reach the desired excellence. The studies by Damato ${ }^{114} 115$ on the referral of patients with uveal melanoma to a tertiary centre partially illustrate this point. The question is "what does the hospital eye service, excluding its primary care services, expect of primary care, in order that, together, they could optimise the patient's prognosis and the ophthalmic health of the population?"

This immediately defines a role for ophthalmology, for it is the ophthalmic profession that is responsible for clarifying the clinical details of this phase and directing ophthalmic primary care training, research, and planning towards them.

A number of parallel debates need to be initiated, interacting with each other and aiming towards one common agenda to include (1) a clinical debate, (2) a primary care models debate, and (3) a workforce debate. Some of these debates have already started in the literature, but they need to be targeted, intensive, dedicated, and taking place in a variety of forums.

\section{CONCLUSION}

Ophthalmic primary care, as a structured discipline, remains undeveloped, borrowing identity from other specialties, despite the presence of clinical ophthalmology at the heart of its services, with abundant relevant ophthalmic expertise. This may be because of the lack of glamour in what is a highly technical and surgically oriented profession, but ophthalmic primary care is a rich and rewarding subject awaiting recognition by ophthalmology's leaders.

\section{Authors' affiliations}

S F Riad, J K G Dart, R J Cooling, Moorfields Eye Hospital, City Road, London ECIV 2PD, UK 


\section{REFERENCES}

1 White Paper. Primary care, delivering the future. $\mathrm{Cm}$ 3512. London: Stationery Office, 1996.

2 Fry J. General practice and primary health care 1940s-1980s. London: The Nuffield Provincial Hospitals Trust, 1988.

3 Simpson L, Lee PR. Primary care: an idea in search a paradigm? Am Fam Physician 1993;47:323-6.

4 World Health Organization. Declaration of Alma-Ata. Report of the International Conference on Primary Health Care, 1978 Sep 6-12; Alma-Ata, USSR. Health for All Series. No 1. Geneva: WHO, 1978

5 Vuori H. Primary health care in Europe-problems and solutions. Community Med 1984;6:221-31.

6 Crombie DL, van der Zee J, Backer P, eds. Summary of proceedings of a workshop on primary health care research. In: The interface study. London: The Royal College of General Practitioners, 1990:55-62.

7 Lewis J. What is primary care? Developments in Britain since the 1960s. Health Care Anal 1998;6:324-9.

8 Sheaff $\mathbf{R}$. What is 'primary' about primary health care? Health Care Anal 1998;6:330-40.

9 Donaldson MS, Yordy KD, Lohr KN, et al, eds. Primary care: America's health in a new era. Washington, DC: Institute of Medicine, 1996.

10 Pedersen LL, Wilkin D. Primary health care: definitions, users and uses. Health Care Anal 1998:6:341-51.

11 Royal College of General Practitioners. Conference of academic organisations in general practice. Developing primary care-the academic contribution. London: Royal College of General Practitioners, 1996.

12 Medical Research Council. Primary health care. MRC Topic Review. London: MRC, 1997

13 Mant D. R\&D in primary care. National Working Group Report. London: Department of Health, 1997.

14 Starfield B. Is primary care essential? Lancet 1994;344:1129-33.

15 Royal College of General Practitioners. The nature of general medical practice. Report from General Practice 27. London: RCGP, 1996.

16 Kupfer C. Public health ophthalmology. Br J Ophthalmo 1987;71:116-7.

17 Rice NCS. In honour of Professor Barrie Jones. Br J Ophthalmo 1987;71:77

18 Starfield B. Primary care-concept, evaluation, and policy. Oxford: Oxford University Press, 1992.

19 Institute of Medicine. A manpower policy for primary health care. IOM publication 78-02. Washington, DC: The Academy, 1978.

20 Dorrell S. Primary care: the future. London: Department of Health, June 1996

21 Littlejohns P. Introduction. In: Littlejohns P, Victor, C, eds. Making sense of a primary care led NHS. Abingdon: Radcliffe Medical Press, 1996: 1-8.

22 Strong NP. How optometrists screen for glaucoma: a survey. Ophthalmic Physiol Opt 1992;12:3-7

23 Tuck MW, Crick RP. Relative effectiveness of different modes of glaucoma screening in optometric practice. Ophthalmic Physiol Opt 1993; 13:227-32.

24 Harris A, Bonell C, Evans T, et al. Commissioning diabetic eye screening by optometrists: a local initiative at the primary-secondary care interface. $J$ Med Screen 1994:1:13-15.

25 Gatling W, Howie AN, Hill RD. An optical practice based diabetic eye screening programme. Diabet Med 1995;12:531-6.

26 Pointer JS, Baranyovits P, O'Malley BP. The Kettering Diabetic Monitoring Programme: twelve months experience of an optometric practice-based scheme. Ophthalmic Physiol Opt 1998;18:401-7.

27 Spencer IC, Spry PG, Gray SF, et al. The Bristol Shared Care Glaucoma Study: study design. Ophthalmic Physiol Opt 1995;15:391-4.

28 Muthucumarana DJ, Rimmer TJ. Cataract surgery and the optometrist. Eye 2000;14:777-8

29 Gaskell A, Mclaughlin A, Young E et al. Direct optometrist referral of cataract patients into a pilot 'one-stop' cataract surgery facility. J R Coll Surg Edinb 2001;46:133-7

30 Ewbank A. The optometrist and primary eye care. Br J Ophthalmol 1997;8:100-1.

31 Hunter PA. Quoted in: Medics warn of eye drugs danger. Optician 1996;211(5551):7

32 Hunter PA. Quoted in: RCO attacks DOH report. Optician 1996;211(5556):7

33 Hunter PA. This Royal College wants co-operation. Optician 1996;212(5558): 11

34 Dart JKG. Eye disease at a community health centre. BM 1986;293: 1477-80

35 Gillam SJ, Ball M, Prasad M, et al. Investigation of benefits and costs of an ophthalmic outreach clinic in general practice. Br J Gen Pract 1995:45:649-52.

36 Chopdar A. Ophthalmic care for the twenty-first century: a perspective based on a recent white paper, 'The New NHS'. J R Soc Health 1999; 1 19:40-1

37 Blach $\mathbf{R}$. The delivery of ophthalmic care: the practitioner, community ophthalmic teams, and contract ophthalmology. $\mathrm{Br} J$ Ophthalmol $2001 ; 85: 1274-5$.

38 Jones NP, Hayward JM, Khaw PT, et al. Function of an ophthalmic "accident and emergency" department: results of a six months survey. $\mathrm{Br}$ J Ophthalmol 1986;292:188-90.

39 Oster J, Culham LE, Daniel R. An extended role for the hospital optometrist. Ophthalmic Physiol Opt 1999;19:351-6.
40 Pecker CO Wishart MS, Jalili IK, et al. Ophthalmic primary care: the Warrington model. Eur Implant Refract Surg 1994;6:2-5.

41 Prasad Rao G, McGalliard JN, Harding SP. Hospital-based primary care centres in ophthalmology. Eye 1997;11:1-2.

42 Claoué $C$, Foss $A$, Daniel $R$, et al. Why are new patients coming to the eye clinic? An analysis of the relative frequencies of ophthalmic disease amongst new patients attending hospital eye clinics in two separate locations. Eye 1997;11:865-8.

43 Aylward GW, Parmar DN. Information technology in ophthalmology-experience with an electronic patient record. $\mathrm{Br}$ Ophthalmol 1999;83:1264-7.

44 Murdoch I. Telemedicine. Br J Ophthalmol 1999:83:1254-6.

45 Hughes P, Gordon P. An optimal balance: primary health care and acute hospital services in London. London: King's Fund Centre, 1992.

46 Sheldrick JH, Wilson AD, Vernon SA, et al. Management of ophthalmic disease in general practice. Br J Gen Pract 1993;43:459-62.

47 Claoué CM. Requirements and characteristics of 500 consecutive patients consulting an ophthalmic medical practitioner. J R Soc Med 1988;8:394-6

48 Bishop AM. Vision screening of children: a review of methods and personnel involved within the UK . Ophthalmic Physiol Opt 1991;11:3-9.

49 Wang YD, Thompson JR, Goulstine DB, et al. A survey of the initial referral of children to an ophthalmology department. Br J Ophthalmol 1990;74:650-3

50 Edwards RS. Ophthalmic emergencies in a district general hospital casualty department. Br J Ophthalmol 1987:71:938-42.

51 Flitcroft DI, Westcott $M$, Wormald $R$, et al. Who should see eye casualties?: a comparison of eye care in an accident and emergency department with a dedicated eye casualty. J Accid Emerg Med $1995 ; 12: 23-7$

52 Tan MM Driscoll PA, Marsden JE. Management of eye emergencies in the accident and emergency department by senior house officers: a national survey. J Accid Emerg Med 1997; 14:157-8.

53 Wong D, Brazier DJ. Primary ophthalmic care: why did patients choose to come to the accident and emergency department? Trans Ophthalmol Soc UK 1986:105:510-2.

54 Shaw DE, Gibson JM, Rosenthal AR. A year in a general ophthalmic outpatient department in England. Arch Ophthalmol 1986;104:1843-6.

55 Hitchings R. Shared care for glaucoma. Br J Ophthalmol 1995;79:626

56 Hicks S. Psycho-social and rehabilitation aspects of acquired visual handicap. Trans Ophthalmol Soc UK 1978;98:252-61.

57 Sheldrick JH, Vernon SA, Wilson A. Study of diagnostic accord between general practitioners and an ophthalmologist. $B M$ 1992;304:1096-8.

58 Lavin MJ, Rose ER. Use of steroid drops in general practice. BM 1986;292:1448-50.

59 Claoué CM, Stevenson KE. Incidence of inappropriate treatment of herpes simplex keratitis with topical steroids. BM 1986;292:1450-1. 60 Buckley SA. Survey of patients taking topical medication at their first presentation to eye casualty. BM 1990;300:1497-8.

61 Featherstone PI, James C, Hall MS, et al. General practitioners' confidence in diagnosing and managing eye conditions: a survey in south Devon. BrJ Gen Pract 1992;42:21-4

62 Shuttleworth GN, Marsh GW. How effective is undergraduate and postgraduate teaching in ophthalmology? Eye 1997;11:744-50.

63 Dayan MR, Fitt AW, Bosanquet RC. General practitioner registrars' opinions of general practice training in ophthalmology: a questionnaire survey in the northern region. Eye 1997;11:496-9.

64 Baneriee S, Beatty S, Tyagi A, et al. The role of ophthalmic triage and the nurse practitioner in an eye-dedicated casualty department. Eye $1998: 12: 880-2$

65 Ilango B, McGalliard JN, Hughes A. The role of nurse practitioners in a primary care eye clinic. Accid Emerg Nurs 2000;8:42-5

66 Marsden J. An evaluation of the safety and effectiveness of telephone triage as a method of patient prioritisation in an ophthalmic accident and emergency service. J Adv Nurs 2000:31:40-9.

67 Pooley JE, Frost EC. Optometrists' referrals to the hospital eye service. Ophthalmic Physiol Opt 1999;19(Suppl 1):16-24

68 Spry PG, Spencer IC, Sparrow JM, et al. The Bristol Shared Care Glaucoma Study: reliability of community optometric and hospital eye service test measures. Br J Ophthalmol 1999:83.707-12.

69 Wormald RP. Preschool vision screening in Cornwall: performance indicators of community orthoptists. Arch Dis Child 1991;66:917-20.

70 McCormick C, Fleming D, Charlton J. Morbidity statistics from general practice. Fourth national study 1991-1992. Series MB5 No 3. London: HMSO, 1995.

71 Walley T, Mantgani A. The UK General Practice Research Database. Lancet 1997;350:1097-9.

72 McDonnell PJ. How do general practitioners manage eye disease in the community? Br J Ophthalmol 1988;72:733-6.

73 Vernon SA. Analysis of all new cases seen in a busy regional centre ophthalmic casualty department during 24-week period. J R Soc Med 1983;76:279-82

74 Chiapella AP, Rosenthal AR.One year in an eye casualty clinic. $\mathrm{Br} J$ Ophthalmol 1985:69:865-70.

75 Bhopal RS, Parkin DW, Gillie RF, et al. Pattern of ophthalmological accidents and emergencies presenting to hospitals. J Epidemiol Community Health 1993;47:382-7.

76 Port MJ, Pope CA. Referrals and notifications by British optometrists. Ophthalmic Physiol Opt 1988;8:323-6.

77 Port MJ. Referrals and notifications by optometrists within the UK: 1988 survey. Ophthalmic Physiol Opt 1989;9:31-5 
78 Hobley AJ, Woodward EG, Port M. Retrospective study of optometric referrals. Ophthalmic Physiol Opt 1992;12:395-9.

79 Sheldrick JH, Vernon SA, Wilson, et al. Demand incidence and episode rates of ophthalmic disease in a defined urban population. BM 1992;305:933-6.

80 Wilkin D, Dornan C. General practitioner referrals to hospital-a review of research and its implications for policy and practice. Manchester: Centre for Primary Care Research, University of Manchester, 1990.

81 Whittaker KW, Ikram K, Anderson DF, et al. Non-communication between ophthalmologists and optometrists. J R Soc Med 1999;92:247-8.

82 Perkins P. Outcome of referrals by optometrists to general practitioners: an 18 month study in one practice. Br J Gen Pract 1990;40:59-61.

83 Kheterpal S, Perry ME, McDonnell PJ. General practice referral letters to a regional ophthalmic accident and emergency department. Eye 1995;96(Suppl):67-9.

84 Tilsley AH. NHS hospitals and primary health care. London: International Hospital Federation, 1985.

85 Dale J, Green J, Glucksman E, et al. Providing for primary care: progress in A\&E. London: Department of General Practice and Primary Care, King's College School of Medicine and Dentistry, 1991.

86 Shapiro J, Perrett K. Introduction. In: Roland M, Shapiro J, eds. Specialist outreach clinics in general practice. Ábingdon: Radcliffe Medical Press, 1998:1-8.

87 Gray SF, Spry PG, Brookes ST, et al. The Bristol shared care glaucoma study: outcome at follow up at 2 years. Br J Ophthalmol 2000;84:456-63.

88 Spencer IC, Coast J, Spry PG, et al. The cost of monitoring glaucoma patients by community optometrists. Ophthalmic Physiol Opt $1995 ; 15: 383-6$.

89 Department of Health. National service framework for diabetes: standards. London: DoH, 2001.

90 Hutchinson A, Mclntosh A, Peters J, et al. Effectiveness of screening and monitoring tests for diabetic retinopathy-a systematic review. Diabet Med 2000;17:495-506

91 Smeeth L, lliffe S. Effectiveness of screening older people for impaired vision in community setting: systematic review of evidence from randomised controlled trials. BM 1998;316:660-3.

92 Fenton PJ, Arnold RC, Wilkins PS. Evaluation of vision in slow-stream wards. Age Ageing 1975:4:43-8.

93 Reinstein DZ, Dorward NL, Wormald RP, et al. 'Correctable undetected visual acuity deficit' in patients aged 65 and over attending an accident and emergency department. Br J Ophthalmol 1993;77:293-6.

94 Little, BC, Aylward GW, Gregson R, et al. Community ophthalmology pilot study. Eye 1993;7:180-3.

95 Rahi JS, Williams C, Bedford $\mathrm{H}$, et al. Screening and surveillance for ophthalmic disorders and visual deficits in children in the United Kingdom. Br J Ophthalmol 2001;85:257-9
96 Reidy A, Minassian DC, Vafidis G, et al. Prevalence of serious eye disease and visual impairment in a north London population: population based, cross sectional study. BM 1998;316:1643-6.

97 Malhotra R, Patel J, Smeeth L. Are elderly people being screened for visual impairment in general practice? Eye 2001;15:98-9.

98 Hillman JG. Audit of elderly people's eye problems and non-attendance at hospital eye service. BN 1994;308:953.

99 Fraser S, Bunce C, Wormald R et al. Deprivation and late presentation of glaucoma: case-control study. BM 2001;322:639-43.

100 Das BN, Thompson JR, Patel R, et al. The prevalence of age related cataract in the Asian community in Leicester: a community based study. Eye 1990;4:723-6.

101 Das BN, Thompson JR, Patel R, et al. The prevalence of eye disease in Leicester: a comparison of adults of Asian and European descent. J $R$ Soc Med 1994;87:219-22.

102 Rauf A, Ong PS, Pearson RV, et al. A pilot study into the ophthalmic disease in the Indian population of Southall. J R Soc Med 1994;87:78-9

103 Sharp PS, Chatuverdi N, Wormald R, et al. Hypertensive retinopathy in Afro-Caribbeans and Europeans. Prevalence and risk factor relationship. Hypertension 1995;25:1322-5.

104 Wormald RP, Basauri E, Wright LA. The African Caribbean Eye Survey: risk factors for glaucoma in a sample of African Caribbean people living in London. Eye 1994;8:315-20.

105 Lam T. Primary health care and the Vietnamese community: a survey in Greenwich. Health Soc Care Community 1994;2:293-9.

106 Burnett A, Peel M. Health needs of asylum seekers and refugees. BM 2001;322:544-7.

107 Coulter A. Why should health services be primary care-led? J Health Serv Res Policy 1996;1:122-4.

108 Majeed FA, Voss S. Performance indicators for general practice. BM 1995;311:209-10.

109 Donabedian A. Evaluating the quality of medical care. Millbank Mem Fund Q 1966:44(Suppl): 166-206.

110 Van Zwanenberg TM, Edwards C. Clinical governance in primary care. In: van Zwanenberg TM, Harrison J, eds. Clinical governance in primary care. Abingdon: Radcliffe Medical Press, 2000:15-27.

111 Royal College of Ophthalmologists. Cataract surgery-the last word (Noticeboard). College News. London: Royal College of Ophthalmologists, Summer 2001.

112 Department of Health. NHS R\&D strategic review: primary care. Report of topic working group. London: DoH, June 1999.

113 Minassian D, Farrow S, Reidy A, et al, eds. A national research strategy for ophthalmology. London: Royal College of Ophthalmologists, 2002.

114 Damato B. Detection of uveal melanoma by optometrists in the United Kingdom. Ophthalmic Physiol Opt 2001;21:268-71.

115 Damato $B$. Time to treatment of uveal melanoma in the United Kingdom. Eye $2001 ; 15: 155-8$. 